\title{
LEVANTAMENTO QUALI-QUANTITATIVO DA ARBORIZAÇÃO URBANA NO MUNICÍPIO DE BURITICUPU, MA
}

\author{
QUALI-QUANTITATIVE SURVEY OF URBAN AFFORESTATION IN THE \\ MUNICIPALITY OF BURITICUPU, MA
}

\author{
Lidia Aguiar de Sousa1, Reinaldo Lucas Cajaiba², Jesuino da Silva Costa Martins², \\ Débora da Silva Colácio ${ }^{1}$, Elson Silva de Sousa ${ }^{2}$, Kleber Sales Pereira²
}

\section{RESUMO}

A arborização urbana oferece vários benefícios para a população, como melhoria microclimática, melhoria na qualidade de vida dos habitantes, permite ainda interação ecológica e conservação das características florística local. O município de Buriticupu - MA localizado na região da Amazônia Legal vem sofrendo ao longo dos últimos anos perda da sua diversidade vegetal urbana. Assim, conhecer a real situação da arborização urbana é de fundamental importância, pois apresenta subsídio para o planejamento e gerenciamento das áreas urbanas. Neste sentido, foi realizado um inventário quali-quantitativo usando o método de censo da arborização de vias públicas de Buriticupu-MA. Os dados foram obtidos considerando aspectos taxonômicos, ecológicos e fitossanidade. Foram catalogados 544 indivíduos distribuídos em 23 famílias e 33 espécies. As famílias mais frequentes foram a Fabaceae e Arecaceae. Das espécies registradas, $51,51 \%$ são nativas do Brasil e $48,49 \%$ exóticas. As espécies Licania tomentosa L. e Ficus benjamina L. apresentaram maior frequência. Espera-se que os resultados auxiliem no planejamento e manejo da arborização de Buriticupu-MA.

Palavras-chave: Levantamento florístico; Inventário arbóreo; Planejamento urbano.

\begin{abstract}
The urban afforestation offers several benefits for the population, such as microclimatic improvement, improvement in the quality of life of the inhabitants, also allows ecological interaction and conservation of the local floristic characteristics. The municipality of Buriticupu - MA is located in the Legal Amazon region and has been suffering loss of its urban plant diversity over the last years. Thus, to know the real situation of the urban afforestation has fundamental importance, since it presents subsidy for the planning and management of the urban areas. In this sense, a qualitative-quantitative inventory was carried out using the census method at the public streets of Buriticupu-MA. Data were obtained considering taxonomic, ecological and phytosanitary aspects. A total of 544 individuals were cataloged in 23 families and 33 species. The more frequency families were Fabaceae and Arecaceae. Of the species recorded, $51.51 \%$ are native to Brazil and $48.49 \%$ are exotic. The species Licania tomentosa L. and Ficus benjamina $\mathrm{L}$. presented greater frequency. It is expected that our results will aid in the planning and management of the Buriticupu-MA afforestation.
\end{abstract}

Keywords: Floristic survey; Tree inventory; Urban planning.

Recebido em 11.03.2019 e aceito em 18.05.2019

1.Graduação em Biologia pelo Instituto Federal do Maranhão - IFMA. Email: la.lidiaaguiar@gmail.com/ deboracolacio55@gmail.com 2 Laboratório de Ecologia e Conservação do Instituto Federal do Maranhão - IFMA. Email: reinaldocajaiba@hotmail.com/ jesuino.martins@ifma.edu.br/ elson.silva@ifma.edu.br/kleber.pereira@ifma.edu.br 


\section{INTRODUÇÃO}

O crescimento exponencial dos ambientes urbanos tem acarretado modificação drástica do ambiente natural. A retirada da vegetação para construção de prédios, indústrias, solidificação das vias, ruas, avenidas e movimentação de veículos promove maior absorção de calor e aumento da temperatura (AQUA; MÜLLER, 2014), além de afetar drasticamente a biodiversidade local (PINHEIRO; SOUZA, 2017).

O processo de urbanização gera uma série de problemas ambientais, incluindo mudanças adversas no microclima e na paisagem, que afetam a qualidade de vida e a saúde da população (CAJAIBA; SILVA, 2017). Nesse aspecto, deve-se considerar a inserção e manutenção de arborização urbana, que desempenha um papel fundamental nas condições térmicas do local, nas interações sociais e na qualidade de vida da população (SANTOS et al., 2017).

A arborização urbana promove clima agradável ao local, a disponibilidade de sombra, diminui a incidência luminosa e em conjunto com as raízes promovem a aeração do solo, amenizam a sensação térmica ao redor, condicionando a mitigação microclimática e a movimentação do ar (ROSSETTI; PELLEGRINO; TAVARES, 2010). Atuam ainda na proteção do solo contra erosão, contenção de ruídos sonoros, bem como na manutenção da fauna urbana, que as utilizam como abrigo e obtenção de alimento (PINHEIRO; SOUZA, 2017).

Apesar dos vários benefícios da arborização, é necessário, no entanto, planejar como esses espaços devem ser desenvolvidos, pois a utilização inadequada de algumas espécies vegetais pode causar impactos negativos sociais e ecológicos dentro do perímetro urbano como, por exemplo, transtornos ao fluxo rotineiro das cidades com quebra de galhos, queda de frutos, interferência da copa na fiação elétrica, das raízes nas calçadas e tubulações de água (ROSSETTI; PELLEGRINO; TAVARES, 2010).

É necessário considerar o tipo de clima e o tipo de solo, pois cada região apresenta características geográficas diferentes, que podem ou não ser favoráveis para o bom desenvolvimento de uma determinada espécie (AQUA; MÜLLER, 2014). Também, deve ser levado em consideração a largura das ruas e vias para melhor adequação do porte das árvores nos intervalos de curto, médio e longo prazo do desenvolvimento (ARAÚJO; ARAÚJO, 2016).

O planejamento das áreas urbanas e o uso de procedimentos de gestão eficazes são necessários para um desenvolvimento urbano ordenado e para proporcionar qualidade de vida à população (IMAM; BANERJEE, 2016). A partir do inventário da arborização urbana, é possível conhecer o acervo florístico das vias e praças da cidade e coletar informações necessárias para um planejamento arbóreo eficiente (SILVA et al., 2018). O município de Buriticupu - MA carece 
de estudos dessa natureza. Dessa forma, o presente trabalho tem como objetivo realizar um inventário quali-quantitativo da arborização de vias públicas da cidade de Buriticupu-MA.

\section{MATERIAL E MÉTODOS}

\section{Local de estudo}

O estudo foi desenvolvido na área urbana do município de Buriticupu - MA, o qual localiza-se na região Pré-Amazônia maranhense, sob as coordenadas $4^{\circ} 20^{\prime} 34$ " de Latitude Sul e 46²4'6" de Longitude Oeste, a aproximadamente $430 \mathrm{~km}$ da capital São Luís (Figura 1). O município tem uma população de 71.723 habitantes, e abrange uma área de $2.545,44$ km² (IBGE, 2010).

Encontra-se inserido no ambiente geológico conhecido como Bacia Sedimentar do Pindaré, que atinge $12,40 \%$ das Bacias do Estado do Maranhão. O relevo é constituído por formações de tabuleiros, separados em faixas por drenos e grotões, situado a uma altitude de 200m acima do nível do mar (LIMA et al., 2017).

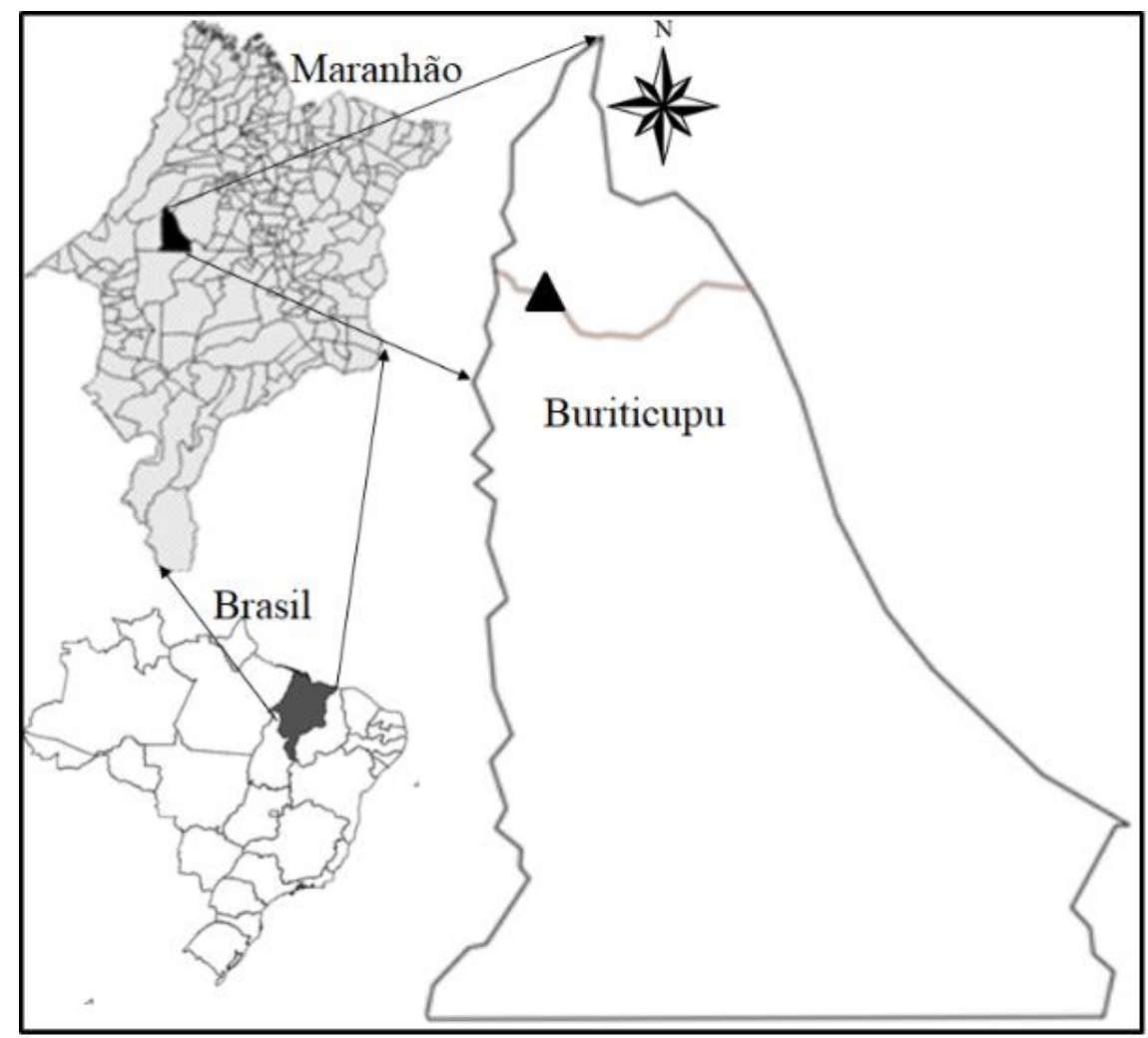

Fonte: Autores (2019)

Figura 1. Localização geográfica do município de Buriticupu no estado do Maranhão, Brasil. O triângulo representa o perímetro urbano

Figure 1. Geographic location of the municipality of Buriticupu in the state of Maranhão, Brazil. The triangle represents the urban perimeter 


\section{Coleta de dados}

Os dados foram coletados entre os meses de fevereiro e março de 2018, através do método de censo das ruas, avenidas e praças da região central da cidade que apresentam arborização urbana, baseada na metodologia proposta por Milano (1984), Santos; Teixeira (2001) Bobrowski (2011), levando em consideração os seguintes aspectos:

a) Características taxonômicas: para a identificação taxonômica dos indivíduos, foram coletadas partes botânicas, registro de imagens e observação da textura de caules e folhas. Foram identificados, até o menor nível hierárquico possível, adotando a nomenclatura científica proposta pelo APG IV (Angiosperm Phylogeny Group IV). A grafia, sinonimização, origem, e distribuição fitogeográfica das espécies foram verificadas utilizando os bancos de dados Lista de Espécies da Flora do Brasil e W3 Tropicos. Para cada espécie identificada, foi referenciado o seu nome popular. Uma parte do material coletado foi dividido em duas partes: uma delas foi depositada no Laboratório de Biologia do Instituto Federal do Maranhão, a outra, foi enviada ao Museu Paraense Emílio Goeldi para análise e confirmação na identificação das espécies.

b) Características ecológicas: quanto à origem fitogeográfica das espécies, consideraram-se nativas nacional aquelas originárias de formações vegetais ocorrentes no Brasil. As espécies que ocorrem em outros ecossistemas diferentes dos que aparecem em território brasileiro, foram consideradas exóticas. Já aquelas espécies que são endêmicas do estado do Maranhão foram classificadas como nativas local.

c) Condições fitossanitárias: i) boa: quando o indivíduo não apresentava sinais aparentes de ataques de pragas, doenças ou injúrias mecânicas; ii) ruim: quando apresentaram sinais de ataques.

d) Qualidade de poda: i) boa: copa bem estruturada, não havendo necessidade de poda; ii) ausente: copa interferindo na fiação, automóveis, pedestres, sendo necessária a retirada; iii) ruim: retirada quantidade excessiva de ramos, denominada poda drástica.

e) Interferência na rede elétrica: i) não: ramos da copa não estavam em contato com os cabos da energia elétrica ou telefônica; ii) sim: quando os ramos da copa estavam em contato com os cabos.

f) Interferência das raízes na calçada: i) não: raízes não expostas e sem danos nas calçadas; ii) sim: raízes expostas com danos nas calçadas.

g) Avanço da copa sobre a rua (medida a distância do meio da copa até a linha de sua projeção sobre a rua). Esses valores foram distribuídos em 3 classes: i) classe 1: <1,5m; ii) classe 2: 1,5 - 3m; iii) classe 3: $>3 \mathrm{~m}$.

h) Área de crescimento ou área livre: foi observada a área livre no local de plantio junto ao solo. Sendo adotados os seguintes critérios de classificação: i) boa: quando plantada em área 
aberta, ou quando suficiente para o crescimento normal do espécime, sem ocupação total da área pelo tronco e sem danificar o passeio; ii) regular: quando a área é suficiente apenas para o desenvolvimento completo do tronco, podendo ainda causar pequenos danos ao passeio; iii) ruim: quando insuficiente para o desenvolvimento completo do tronco, causando, ou com possibilidades de causar danos significativos ao passeio e iv) ausente: quando não houver espaço para o crescimento secundário, estando o cimento junto à base do mesmo, geralmente causando danos.

i) Altura total: foi verificada a altura total da árvore em metros. Foi considerada desde a superfície do solo, até as folhas no ápice do galho mais alto. Foram classificadas em: i) muda: $<1 \mathrm{~m}$; ii) pequeno porte:> 1-2 m; iii) médio porte:> 3-6 m; iv) grande porte:> $6 \mathrm{~m}$.

j) Circunferência a altura do peito - CAP: foram inventariadas todas as espécies arbóreas existentes na arborização urbana com CAP $\geq 10 \mathrm{~cm}$. As aferições foram realizadas a uma altura de 1,30 metros.

Após a coleta dos dados, foi calculado o número de vezes que os indivíduos de cada espécie foram observados na arborização urbana (frequência absoluta) e a proporção do número de observações de uma determinada espécie em relação ao total de observações (frequência relativa), sendo expressa em termos percentuais.

\section{RESULTADOS E DISCUSSÃO}

Foram avaliados um total de 544 indivíduos distribuídos em 23 famílias botânicas e 33 espécies. As famílias com maior frequência foram Arecaceae (5 espécies e 29 indivíduos) e Fabaceae (5 espécies e 28 indivíduos) (Tabela 1). A alta representatividade de Fabaceae e Arecaceae foi encontrada em outros estudos realizados sobre arborização urbana em cidades brasileiras (TISCHER; FORTE; MORAES, 2014; AQUA; MÜLLER, 2014; SILVA, et al., 2018). A prevalência dessas famílias é justificada pela capacidade adaptativa e estratégias de sobrevivência para diferentes ambientes (RODRIGUES; BRASILEIRO; MELO, 2014).

Tabela 1. Espécies catalogadas na arborização urbana no município de Buriticupu-MA, família botânica, nome científico e popular, origem, total de indivíduos por espécies e frequência relativa-Fr

Table 1. Species cataloged in the urban afforestation in the municipality of Buriticupu-MA, botanical family, scientific and popular name, origin, total of individuals by species and relative frequency$\mathrm{Fr}$

\begin{tabular}{ccccc}
\hline Família/Nome Científico & Nome popular & Origem & Total & $\begin{array}{c}\text { Fr. } \\
(\%)\end{array}$ \\
\hline $\begin{array}{c}\text { CRYSOBALANACEAE } \\
\text { Licania Tomentosa L. }\end{array}$ & Oiti & NaBr/ ExMa & 18 & 34,7 \\
MORACEAE & & & 9 & 4 \\
Ficus benjamina L. & Ficus & ExBr & 98 & $\begin{array}{c}18,0 \\
1\end{array}$
\end{tabular}




\begin{tabular}{|c|c|c|c|c|}
\hline IELIACEAE & & Fy $\mathrm{Rr}$ & & 123 \\
\hline Família/Nome Científico & Nome popular & Origem & $\begin{array}{c}\text { Tot } \\
\text { al }\end{array}$ & $\begin{array}{l}\text { Fr. } \\
(\%)\end{array}$ \\
\hline ANACARDIACEAE & & & & \\
\hline Mangifera indica L. & Manga & $\mathrm{ExBr}$ & 27 & 4,96 \\
\hline $\begin{array}{l}\text { Anacardium occidentale L. } \\
\text { BIGNONIACEAE }\end{array}$ & Caju & $\mathrm{NaBr} / \mathrm{NaMa}$ & 2 & 0,37 \\
\hline Tabebuia sp. & Ipê & $\mathrm{NaBr} / \mathrm{NaMa}$ & 30 & 5,51 \\
\hline $\begin{array}{c}\text { Tecoma stans (L.) Juss.ex Kunth } \\
\text { NYCTAGINACEAE }\end{array}$ & Ipê-de-jardim & $\mathrm{ExBr}$ & 1 & 0,18 \\
\hline $\begin{array}{l}\text { Bougainvillea glabra Choisy } \\
\text { COMBRETACEAE }\end{array}$ & Buganvília & $\mathrm{NaBr} / \mathrm{ExMa}$ & 17 & 3,13 \\
\hline $\begin{array}{c}\text { Terminalia catappa L. } \\
\text { RUTACEAE }\end{array}$ & Amêndoa & $\mathrm{NaBr} / \mathrm{ExMa}$ & 6 & 1,10 \\
\hline $\begin{array}{l}\text { Aurantium sinense Mill. } \\
\text { LECYTHIDACEAE }\end{array}$ & Laranja & $\mathrm{NaBr} / \mathrm{ExMa}$ & 1 & 0,18 \\
\hline $\begin{array}{l}\text { Lecythis lurida (Miers) S .A. Mori } \\
\text { FABACEAE }\end{array}$ & Sapucainha & $\mathrm{NaBr} / \mathrm{NaMa}$ & 1 & 0,18 \\
\hline Tamarindus indica L. & Tamarindo & $\mathrm{ExBr}$ & 1 & 0,18 \\
\hline Anadenanthera pavonina L. & Pau-brasil-falso & ExBr & 1 & 0,18 \\
\hline Cassia siamea L. & Acácia & $\mathrm{NaBr} / \mathrm{NaMa}$ & 23 & 4,23 \\
\hline Bauhinia sp. L. & Pata-de-vaca & $\mathrm{NaMa}$ & 2 & 0,37 \\
\hline $\begin{array}{l}\text { Erythrina variegata } \mathrm{L} . \\
\text { MALVACEAE }\end{array}$ & Brasileirinho & $\mathrm{NaBr} / \mathrm{ExMa}$ & 1 & 0,18 \\
\hline $\begin{array}{l}\text { Theobroma cacao L. } \\
\text { MIRTACEAE }\end{array}$ & Cacau & $\mathrm{NaBr} / \mathrm{NaMa}$ & 1 & 0,18 \\
\hline Syzygium jambos (L.) Alston & Jambo & $\mathrm{NaBr} / \mathrm{ExMa}$ & 2 & 0,37 \\
\hline $\begin{array}{l}\text { Syzygium cumini (L.) Skeels } \\
\text { VERBENACEAE }\end{array}$ & Azeitona & $\mathrm{NaBr} /$ ExMa & 1 & 0,18 \\
\hline $\begin{array}{l}\text { Duranta erecta L. } \\
\text { MALVACEAE }\end{array}$ & Pingo-de-ouro & $\mathrm{NaBr} / \mathrm{ExMa}$ & 4 & 0,74 \\
\hline $\begin{array}{c}\text { Hibiscus andersonii Krapov. \& Fryxell } \\
\text { APOCYNACEAE }\end{array}$ & Hibisco & $\mathrm{NaBr} / \mathrm{ExMa}$ & 1 & 0,18 \\
\hline Plumeria pudica L. & $\begin{array}{l}\text { Jasmim-do- } \\
\text { caribe }\end{array}$ & $\mathrm{ExBr}$ & 1 & 0,18 \\
\hline ARECACEAE & & & & \\
\hline $\begin{array}{c}\text { Roystonea oleraceae (Jacq.) O. F. } \\
\text { Cook }\end{array}$ & $\begin{array}{l}\text { Palmeira- } \\
\text { imperial }\end{array}$ & $\mathrm{ExBr}$ & 9 & 1,65 \\
\hline Whashingtonia filifera (L. linden) & Palmeira-leque & $\mathrm{ExBr}$ & 1 & 0,18 \\
\hline $\begin{array}{l}\text { Bismarchia nobilis Hildebr. \& H. } \\
\text { Wendl. }\end{array}$ & Palmeira-azul & $\mathrm{ExBr}$ & 1 & 0,18 \\
\hline $\begin{array}{c}\text { Veitchia merrillii (Becc) H. E. Moo } \\
\text { CYCADACEAE }\end{array}$ & Palmeira & $\mathrm{ExBr}$ & 4 & 0,74 \\
\hline $\begin{array}{l}\text { Cycas revoluta Thunb. } \\
\text { RHAMNACEAE }\end{array}$ & Cica & $\mathrm{ExBr}$ & 4 & 0,74 \\
\hline $\begin{array}{l}\text { Ziziphus joazeiro Mart. } \\
\text { RUBIACEAE }\end{array}$ & Juá & $\mathrm{NaBr} / \mathrm{NaMa}$ & 1 & 0,18 \\
\hline $\begin{array}{l}\text { Morinda citrifolia } \mathrm{L} \text {. } \\
\text { EUPHORBIACEAE }\end{array}$ & Noni & $\mathrm{ExBr}$ & 1 & 0,18 \\
\hline $\begin{array}{c}\text { Jatropha gossypiifolia L. } \\
\text { LYTRACEAE }\end{array}$ & Pião-roxo & $\mathrm{NaBr} / \mathrm{NaMa}$ & 1 & 0,18 \\
\hline $\begin{array}{l}\text { Lagerstroemia indica L. } \\
\text { RUBIACEAE }\end{array}$ & resedá & $\mathrm{ExBr}$ & 2 & 0,37 \\
\hline Ixora coccinea L. & Ixora & $\mathrm{ExBr}$ & 58 & $\begin{array}{c}10,6 \\
6\end{array}$ \\
\hline $\begin{array}{c}\text { AGAVACEAE } \\
\text { Agave sisalana Perrine }\end{array}$ & Piteira-do-caribe & ExBr & 29 & 5,38 \\
\hline Total & & & 544 & 100 \\
\hline
\end{tabular}


${ }^{*} \mathrm{NaBr}=$ nativa do Brasil; $\mathrm{ExBr}=$ exótica para o Brasil; $\mathrm{NaMa}=$ nativa do Maranhão; ExMa = exótica para o Maranhão

Em relação à origem, das 33 espécies encontradas no presente estudo, 51,51\% (17 espécies) foram consideradas nativas do Brasil e 48,49\% (16 espécies) foram consideradas exóticas do Brasil. Para o ecossistema maranhense, das 33 espécies apenas 24,25\% (8 espécies) foram consideradas endêmicas do ecossistema maranhense. Das espécies nativas do Brasil, as mais comuns foram oiti (Licania tomentosa L.) com 189 indivíduos, ipê (Tabebuia sp.) com 30 indivíduos e acassia (Cassia siamea L.) com 23 indivíduos. Por outro lado, as espécies exóticas mais frequentes foram a ficus (Ficus benjamina L.) com 98 indivíduos e ixora (Ixora coccinea L.) com 58 indivíduos (Tabela 1). Apesar de uma maior prevalência das espécies nativas, a inserção de plantas exóticas na arborização urbana pode se tornar em uma situação preocupante, principalmente devido à falta de conhecimento do seu potencial de adaptação, competição com espécies nativas, além do potencial de toxicidade para a fauna local (ALENCAR et al., 2014).

As espécies oiti $(34,74 \%)$ e ficus (18,01\%) obtiveram elevados números de indivíduos representando metade da arborização, ultrapassando o limite de $10 \%$ que uma espécie pode representar dentro de uma população geral (GREY; DENEKE, 1978). O alto índice de uma única espécie pode torná-la vulnerável ao ataque de pragas ou sofrer com a desconfiguração do ambiente, levando-a a eliminação da espécie além de tornar a paisagem homogênea e pouco agraciável (ALENCAR et al., 2014; SILVA et al., 2018).

Estudos têm demonstrado a utilização de poucas espécies na arborização urbana (ALMEIDA; RONDON NETO, 2010; ROMANI et al., 2012), assim como a prevalência das espécies oiti e ficus (ROLON; SIQUEIRA, 2018; SILVA et al., 2018). A preferência pela utilização dessas duas espécies na arborização urbana é devido ao fato de possuírem copas frondosas e disponibilizarem sombra durante todo o ano, além de serem de rápido crescimento e fácil adaptação ao ambiente (ALBERTIN et al., 2011; SILVA et al., 2018; OLIVEIRA; SANCHES; MUSIS, 2013).

Sobre as condições fitossanitárias, 63,60\% (346 indivíduos) apresentaram boas condições, ou seja, folhagem e coloração firme, poda leve, ausência de pragas e sem injúrias mecânicas, enquanto 36,40\% (198 indivíduos) estavam em condições ruins, acometidas principalmente por injúrias mecânicas, outras com mutilações em seus galhos e troncos, ataques de pragas como formigas, cupins, fungos e diversos herbívoros. Os danos causados por insetos sugadores e cupins, podem interferir na integridade e longevidade da planta. Esses, são problemas recorrentes que acometem árvores de ambientes urbanos e que, em geral, podem ser resolvidos com a substituição de alguns indivíduos e/ou espécies (ROLON; SIQUEIRA, 2018). 
Com relação à poda, 63,79\% (347 indivíduos) apresentaram boa poda, 22,06\% (120 indivíduos) apresentaram poda ruim, ou seja, a poda foi feita de forma drástica que provocou prejuízo às plantas e 14,15\% (77 indivíduos) estavam com necessidades de poda, por interferir no deslocamento de automóveis, pedestre e na fiação elétrica. A retirada drástica danifica a estrutura natural da planta, além de colocar em risco a fitossanidade (ARAÚJO; ARAÚJO, 2016), impossibilitando as funções fotossintéticas e a capacidade de sombreamento. Nesse sentido, são necessárias medicas de controle para a escolha de espécies para evitar deformidades nas estruturas vegetais (ALENCAR, et al., 2014).

Em relação à interferência das raízes nas calçadas, 94\% (511 indivíduos) não apresentaram danos às calçadas, 6\% (33 indivíduos) apresentaram danos nas calçadas contribuindo para o mau aproveitamento das calçadas. A área de crescimento foi classificada como boa para o desenvolvimento do caule em 59,74\%, (325 indivíduos), 21,32\% (116 indivíduos) apresentaram área regular com espaço limitado apenas ao desenvolvimento do caule, 7,72\% (42 indivíduos) foram classificados como ruim, com risco de seus troncos serem sufocadas e 11,21\% (61 indivíduos) com ausência de espaço para o desenvolvimento do caule.

A má escolha de espécies pode trazer problemas futuros para o desenvolvimento do tronco e do sistema radicular, podendo obstruir, quebrar ou trincar as calçadas, deixando-as impróprias para o uso de pedestres (LEITÃO; BARBOSA, 2017). A área de crescimento da planta deve ser compatível e livre de cobertura sólida para o desenvolvimento completo até sua fase adulta, pois a falta de espaço pode limitar a permeabilidade das raízes aos recursos hídricos pela pouca infiltração de água (ARAÚJO; ARAÚJO, 2016).

Para o avanço da copa sobre a rua, verificou-se um total de 96,32\% (524 indivíduos) com avanço inferior a 1,5m, 2,94\% (16 indivíduos) com avanço de >1,5-3m, e 0,74\% (4 indivíduos) com avanço $>3 \mathrm{~m}$ sobre a rua. Para ruas e calçadas estreitas deve-se priorizar espécies de copa estreita, alta ou piramidal, evitando crescimento de galhos laterais. Estudos revelam que a primeira ramificação abaixo de $2 \mathrm{~m}$ interfere de forma negativa no fluxo dos pedestres (AQUA; MÜLLER, 2014).

Quanto ao porte, a maioria dos indivíduos foram classificados como médio porte (>3$6 \mathrm{~m})$, seguidos por indivíduos de pequeno porte (1-3m) (Figura 2). Sobre a circunferência a altura do peito da arborização urbana, no geral, mostraram-se compatíveis ao porte. As espécies que apresentaram maior circunferência foram: a palmeira-imperial (Roystonea oleraceae Jacq.), palmeira- leque (Washingtonia filifera L. Linden), palmeira-azul (Bismarchia nobilis Hilderbr.) e ficus ( $F$. benjamina) variando entre $0,75 \mathrm{~m}$ a $1,8 \mathrm{~m}$. 


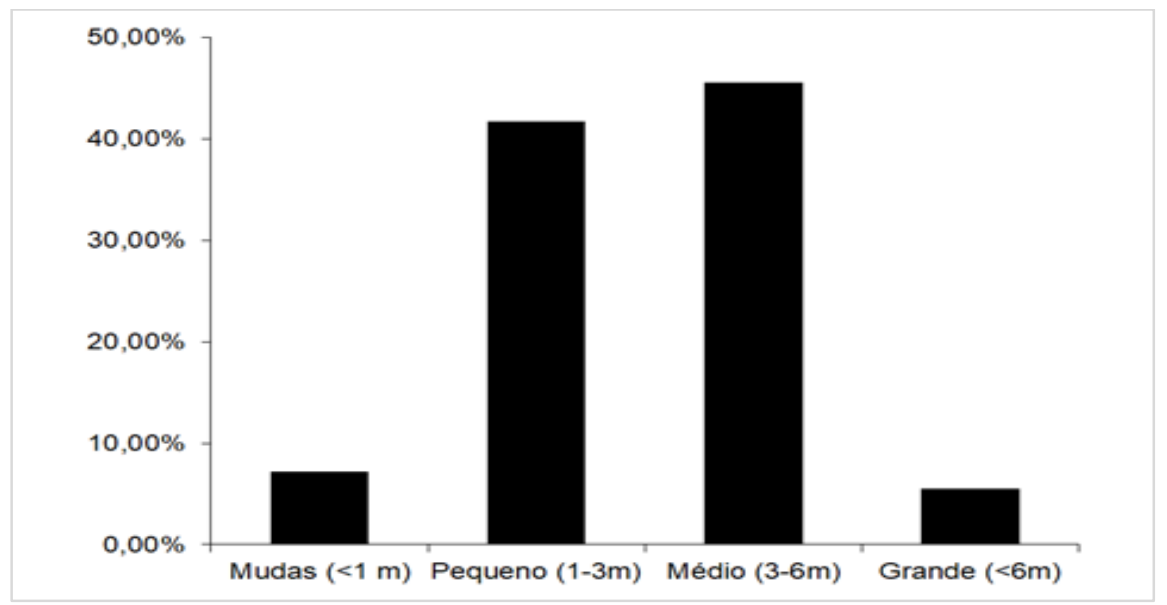

Figura 2. Porte das árvores encontradas nas ruas e avenidas do município de Buriticupu, Ma Figure 2. Size of the trees found in the urban afforestation of the municipality of Buriticupu, Ma

Dentro da classificação de pequeno porte encontram-se plantas arbustivas ornamentais como ixora (Ixora coccinea L.) e hibisco (Hibisco andersonii Krapov. \& Fryxell) que contribuem com o valor estético da paisagem. As de médio porte desempenham melhor as funções de sombreamento além de serem ideais para compor a arborização de determinados locais, pois evitam conflitos com fiações elétricas e equipamentos públicos da cidade (TISCHER; FORTE; MORAES, 2014).

As árvores de grande porte apresentam quesitos fundamentais, que as tornam importantíssimas na arborização urbana, quando bem planejadas e plantadas em locais apropriados desempenham com eficiência sua principal função dentro das cidades: fazem sombra com suas copas, suas folhas por estarem em maior quantidade e serem mais distribuídas desempenham melhor a absorção dos raios solares e liberação de oxigênio pelo processo de fotossíntese, com isso, efetuam maior mitigação microclimática do ambiente e aumento do perímetro de proteção do solo no período de chuva (OLIVEIRA; SANCHES; MUSIS, 2013; SILVA et al., 2018).

\section{CONCLUSÕES}

A arborização urbana de Buriticupu, apresenta predomínio de espécies nativas do Brasil, mas poucas nativas do ecossistema maranhense. A análise desenvolvida mostra a necessidade de ações para a poda e cuidados com a fitossanitdade. Neste sentido, faz-se necessário que medidas de gestão contempladas com as normas técnicas sejam estabelecidas de acordo com a necessidade estrutural da cidade para que ocorra tanto a melhoria da qualidade da poda quanto manutenção da arborização já existente. Recomenda-se a realização de novos plantios priorizando o uso de espécies nativas locais, favorecendo a biodiversidade.

\section{AGRADECIMENTOS}


Os autores agradecem ao Instituto Federal do Maranhão, campus Buriticupu pelo apoio logístico e aos alunos voluntários do curso de Biologia/ Ifma pelo suporte aos trabalhos de campo. Somos gratos também a dois revisores anônimos por contribuições valiosas ao manuscrito. RLC agradece ao CNPQ pela bolsa de Pós-Doutorado (Processo no PDJ 153480/2018-1).

\section{REFERÊNCIAS}

ALBERTIN, R. M.; ANGELIS, R.; ANGELIS NETO, G.; ANGELIS, B. L. D. Diagnóstico qualiquantitativo da arborização viária de nova esperança, Paraná, Brasil. Revista da Sociedade Brasileira de Arborização Urbana, Curitiba, PR, v. 6, n. 3, p. 128-148, 2011.

ALENCAR, L. S.; SOUTO, P. C.; MOREIRA, F. T. A.; SOUTO, J. S. BORGES, C. H. A. Inventário quali-quantitativo a arborização urbana em São João do Rio do peixe-PB. Revista Agropecuária Científica no Semiárido, Patos, PB, v. 10, n. 2, p. 117-124, 2014.

ALMEIDA, D. N.; RONDON NETO, R. M. R. Análise da arborização urbana de três cidades da região norte do Estado de Mato Grosso. Acta Amazonica, Manaus, AM, v. 40, n. 4, p. 647-656, 2010.

AQUA, M. D.; MÜLLER, N. T. G. Diagnóstico da arborização urbana de duas vias na cidade de Santa Rosa-RS. Revista da Sociedade Brasileira de Arborização Urbana, Curitiba, PR, v.9, n. 3, p. 141-145, 2014.

ARAÚJO, M. N.; ARAÚJO, A. J. Arborização urbana. Série de cadernos técnico da agenda parlamentar: Paraná-PR, 2016.

BOBROWSKI, R. Estrutura e dinâmica da arborização de ruas de Curitiba, Paraná, no período 1984-2010. 144f. Dissertação (Mestrado em Engenharia Florestal) - Universidade Federal do Paraná, Curitiba, 2011.

CAJAIBA, R. L.; SILVA, W. B. Levantamento de entomofauna em arborização urbana no município de Uruará, Pará, norte do Brasil. Biota Amazônia, Macapa, AP, v. 7, n. 1, p. 69-73, 2017.

GREY, C.; DENEKE, F. Urban Forestry. John Wiley. Chichester, p. 279, 1978.

INSTITUTO BRASILEIRO DE GEOGRAFIA E ESTATíSTICA (IBGE). Censo Demográfico, 2010. Disponível em: <http://www.ibge.gov.br>. Acesso em: 12 janeiro de 2018.

IMAM, A. U. K.; BANERJEE, U. K. Urbanisation and greening of Indian cities: Problems, practices, and policies. Ambio, Switzerland, v. 45, p. 442-457, 2016.

JBRJ. Instituto de Pesquisa Jardim Botânico do Rio de Janeiro. Jabot - Banco de Dados da Flora Brasileira. Disponível em: <http//jabot.jbrj.gov.br/>. Acesso em: 20/mar/2018.

LEITÃO, F. S.; BARBOSA, G. S. Arborização urbana de vias públicas: planejamento passeiocalçada. Boletim do observatório ambiental Alberto Ribeiro Lamego, Campos dos Goytacazes, RJ, v. 11 n. 1, p. 151-168, 2017. 
LIMA, J. S.; MARTINS J. S. C.; PEREIRA, K. S.; SOUSA, E. S, CAJAIBA, R. L. Composição gravimétrica de resíduos sólidos em escolas públicas e privadas no município de Buriticupu, MA. Scientia Amazonia, Manaus, AM, v. 6, n. 3, p. 11-16, 2017.

MILANO, M. S. Avaliação e análise da arborização de ruas de Curitiba-PR. Curitiba, 1984. 130f. Dissertação (Mestrado em Ciências Florestais) -Universidade Federal do Paraná, Curitiba, PR, 1984.

OLIVEIRA, A. S.; SANCHES, L.; MUSIS, C. R. Benefícios da arborização em praças urbanas O caso de Cuiabá/MT. Revista Eletrônica em Gestão, Educação e Tecnologia Ambiental, Santa Maria, RS, v. 9, n. 9, p. 1900-1915, fev 2013.

PINHEIRO, C. R.; SOUZA, D. D. A importância da arborização e sua influência no microclima. Revista Gestão \& Sustentabilidade Ambiental, Florianópolis, SC, v. 6, n. 1, p. 67-82, 2017.

RODRIGUES, J. S.; BRASILEIRO, J. C-B.; MELO, J. I. M. Flora de um inselberg na mesorregião agreste do estado da Paraíba-Brasil. Polibotánica, Colonia Santo Tomás, DF, v. 37, p. 47-61, 2014.

ROLON, M. S.; SIQUEIRA, M. V. B. M. Diagnóstico arbóreo comparativo em bairros de Lençóis Paulista - SP. Revista da Sociedade Brasileira de Arborização Urbana, Curitiba, PR, v. 13, n. 1, p. 43-56, 2018.

ROMANI, G. N.; GIMENES, R.; SILVA, M. T.; PIVETTA, K. F. A. L.; BATISTA. G. S. Análise qualiquantitativa da arborização na praça xv de novembro em Ribeirão Preto - SP, Brasil. Revista Arvore, Viçosa, MG, v. 36, n. 3, p. 479-487, 2012.

ROSSETI, A. I. N.; PELLEGRINO, P. R. M.; TAVARES, A. R. As árvores e suas interfaces no meio urbano. Revista da Sociedade Brasileira de Arborização Urbana, Curitiba, PR, v. 5, n. 1, p. 1-24, 2010.

SANTOS, J. J. A.; SANTOS, A. E. S.; SILVA, A. M.; SANTOS, V. C.; SANTANA NETO, D. C. S. Levantamento botânico de plantas utilizadas na arborização urbana de Nova Palmeira, Paraíba. Revista Verde de Agroecologia e Desenvolvimento Sustentável, Pombal, PB, v. 12, n. 5, p. 866-873, 2017.

SANTOS, N. R. Z.; TEIXEIRA, I. F. Arborização de vias públicas, ambiente X vegetação. Rio de Janeiro, RJ, Instituto Souza Cruz-Santa Cruz do Sul, 2001. 135p.

SILVA, L. A.; SOUSA, C. S.; PARRY, M. M.; HERRERA, R. C.; OLIVEIRA, F. P. M.; PARRY, S. M. Diagnóstico da arborização urbana da cidade de Vitória do Xingu, Pará, Brasil. Revista da Sociedade Brasileira de Arborização Urbana, Curitiba, PR, v. 13, n. 1, p. 57-72, 2018.

TISCHER, J. C.; FORTE, A. R.; MORAES, C. P. Análise qualiquantitativa de indivíduos arbóreos das praças centrais do município de Leme, SP. Revista da Sociedade Brasileira de Arborização Urbana, Curitiba, PR, v. 9, n. 3, p. 49-64, 2014.

MISSOURI BOTÂNICO GARDEM. W3 Tropicos: Nomeclatura database and associated authority files. Disponível na internet em: http:/www.tropicos.org/> Acesso em: 20 mar. 2018. 